\title{
Information required in managing the design process of refurbishment projects
}

\author{
A. S. Ali, S. N. Kamaruzzaman \& Z. Abdul-Samad \\ The Faculty of Built Environment, University of Malaya, Kuala Lumpur, \\ Malaysia
}

\begin{abstract}
Building refurbishment is an important sector in the Malaysian construction industry. The high demand for refurbishment projects is due to an increase in the number of deteriorating and obsolete buildings. However, refurbishment projects are more difficult to manage compared to new-builds. The problem mainly derives from the lack of information available to perform a task, especially during the initial stage of the design process. Many authors on management agree on the importance of the design process towards the success of refurbishment projects. Even though design cost contributes a small percent of total project cost, the performance of the refurbishment projects is much affected by the design process. Similarly, about a quarter of refurbishment project time is lost due to problems in design. The main reason for lost time was rework in design due to errors made during the design process. The construction performances have always been reduced by the difficulty of managing the design process. Therefore, management in the design process needs to be improved in order to produce accurate design before work starts on site.

This study aims to discuss methods of obtaining design information in refurbishment projects and shows how the methods could affect performance of refurbishment design. The data was obtained from literature reviews, semistructured interviews with 21 principal architects and a questionnaire survey. The results indicate that a site survey was considered the most important method of obtaining design information during the design process of refurbishment projects. In contrast, destructive and non-destructive tests were rated the least important amongst all the method of obtaining information during the design process.
\end{abstract}

Keywords: design information, refurbishment projects, uncertainty. 


\section{Introduction}

In a highly competitive construction market, designers need to respond efficiently in order to meet client requirements. Efficient management in the design process is paramount to providing quality designs within budgeted costs and to ensure that the project runs smoothly. However, the management of the design process is a difficult task. The design process is made up of a combination of intense technical and social activities (Bucciarelli [7]; Bordass and Leaman [6]). The process involves integration of technical knowledge and a greater interaction among the various participants, such as clients, designers, users and contractors.

Many management authors agree on the importance of the design process towards the success of construction projects (Chua et al. [9]). Even though design cost contributes only about 10 percent of total project cost, the performance of the refurbishment projects is much affected by the design process (Stermen [21]). Furthermore, Bibby et al. [5] discovered that construction performance in the UK has always being reduced by the difficulty of managing the design process. Therefore, management in the design process needs to be improved in order to produce accurate designs before work starts on site.

Refurbishment in this study refers to upgrade, major repairs work, renovations, alterations, conversions, extensions and modernization of existing building, but excludes routine maintenance and cleaning work (Quah [18]). In refurbishment projects, the problem in the design process is further compounded by the project uncertainty. Researchers such as Egbu [11] and Ali [2] have provided evidence of the complexity and uncertainty of refurbishment projects. The problem mainly derives from the lack of information available to perform a task, especially during the initial stage of the design process. Information is very important because many decisions need to be finalized during the early stage of design. Therefore, the rationale for conducting this study is to improve the management of information especially on the methods used to obtain design information during the design process of refurbishment projects.

\section{Information on the design process of refurbishment projects}

Uncertainty is related to the amount of information available to perform a task. Baldwin et al. [4] have described information as a 'fuel of design' where all team members are required to undertake their design tasks. Quality information would help the designers to produce accurate and complete designs as required. Initial information available at the early stage of design is vital since the initial concept forms the basis for the final design (Mackinder and Marvin [13]).

Problems in the design process arise when designers start their work based on unavailable information or incomplete information, and when different quality of information is used for different design tasks (Ali et al. [3]). Problems of designing refurbishment projects include the lack of information available about the operating facilities, space limitations and maintaining existing design 
(McKim et al. [15]). Similarly, Sanvido and Norton [20] highlighted the fact that untimely information makes the design process more complex. A variety of problems such as inappropriate space, routing of services and insufficient access may crop up in the initial stage of the design process due to inaccurate, incomplete or untimely information. The lack of information could become an obstacle for the designers to complete tasks successfully. Information is very important because many decisions need to be finalized during the schematic design stage. McGeorge [14] emphasized the need for coordinating the collection, processing, storage and transmission of information that is essential for effective design. In the early stage of refurbishment projects, the designers need to gather as much information as they can from existing buildings before starting their design work. Design in refurbishment is different from design in new-build projects because designers have to suit their designs to the existing structure of the building. Because of this, many designers are less interested in being involved in refurbishment work, due to the limitation put on their creativity (Daoud [10]).

Furthermore, refurbishment projects became even more uncertain when they involve structural modifications, which are sensitive, dangerous and difficult operations. Extra precautions need to be taken when dealing with structural modifications (Daoud [10]). Temporary supports, which are normally needed for demolition and alteration of building structure, are more widely used in this type of refurbishment work compared with new-build projects (Friedman and Oppenheimer [12]). A refurbishment project is normally dangerous when it involves demolition work. In this case, the designers are required to have extra knowledge of the building structure in order to produce a design for temporary supports such as scaffolding and shoring. It is the responsibility of the designers to ensure that the temporary supports used could withstand the necessary loads and that the site conditions are safe to deliver what they have designed during the commencement of alteration works. Hence, the temporary support needs to be designed by a certified engineer. The content of services work in refurbishment projects is another major factor that contributes to design uncertainty of refurbishment projects (Rahmat [19]). Hidden items such as piping and electrical cables induce designers to make assumptions on the services routing in their design. As a result, changes of design frequently happen during the construction stage, due to inaccurate routing design.

To overcome the problem of faulty and inaccurate design information, the use of appropriate techniques for information gathering such as building surveys are required (Quah [18]; Aho et al. [1]). Building surveys are important since they provide information accurately on the condition of the buildings, the actual scope of work; clarify ambiguities in the existing documents and confirm that the existing building could be adapted for the proposed new uses. Other sources of information that could be used to obtain information were client's brief, contractor input, archive document and testing (Ali [2]). The building survey exercise is more precise if it is combined with a non-destructive diagnosis technique (Quah [18]). This technique is capable of reducing time and cost for the survey and at the same time increasing the accuracy of the survey result. 


\section{Research methodology}

This study designed with the triangulation technique, which consists of quantitative and qualitative approaches. Semi-structured interview were use for qualitative part whereas for quantitative, the postal questionnaires survey has been used for data collection method. In order to get a high response rate, the questionnaire was design short and simple and that did not take long time for the respondent to answer. The respondents for this study consisted of professional architects who are registered with the Board of Architect Malaysia. 264 architects with refurbishment design experience identified appropriate to participate in the survey. A questionnaire sent to the final list of 243 architects. After filtration made from 98 replied questionnaires, 88 questionnaires were found to be useful for analysis, giving a response rate about 36 percent. The replied questionnaires represent 82 different refurbishment projects with a contract value of more than RM 1,000,000.00 (USD 300,000.00). For data transformation, Software Package of Social Science (SPSS) version 16.0 for analysis data was used. Descriptive method of statistical and associative test was employed to find out significant correlation between methods of obtaining information on performance of refurbishment projects. The profile of the respondents shows in Table 1. The profile shows almost two-third of the respondents were principal architects. The result shows that nearly ninety-five percent of them had more that 10 years of experience in the construction industry. This suggests that the data collected from the survey are reliable.

Table 1: $\quad$ Profile of respondents.

\begin{tabular}{|l|r|}
\hline Position & Percentage, N=88 \\
\hline Principal & 71 \\
\hline Senior Architect & 14 \\
\hline Architect & 11 \\
\hline Others & 4 \\
\hline
\end{tabular}

To rank the most important methods of obtaining information, the relative importance index (RII) was used. Five point scale used in the questionnaire was transformed to relative importance index to determine ranks of each variables. The RII was employed using the following equation (Chan and Kumaraswamy [8]):

Relative importance index, RII $\quad \frac{\sum \mathrm{W}}{\mathrm{A} \times \mathrm{N}} \quad, \quad(0 \leq$ index $\leq 1)$

where : $\quad \mathrm{W}=$ weighting given to each factor by respondents; ( 1 to 5$)$

$\mathrm{A}=$ highest weight; 5

$\mathrm{N}=$ Total number of respondents 


\section{Result and discussion}

Table 2 shows the result of the analysis using the 'Relative Importance Index' (RII) for method of obtaining information. The result indicates that site inspections are relatively the most important method for obtaining information during the design process of refurbishment projects. The destructive and nondestructive tests are the least important among all methods of obtaining information during the design process.

Table 2: $\quad$ RII result of methods obtaining information.

\begin{tabular}{lcc}
\hline Method Obtaining Information & RII, N=88 & Rank \\
\hline Site Survey & 0.97 & 1 \\
Client's Brief & 0.84 & 2 \\
Contractor's Input & 0.77 & 3 \\
Design Team's Input & 0.74 & 4 \\
Archive Document & 0.71 & 5 \\
Destructive \& Non Destructive Test & 0.70 & 6 \\
\hline
\end{tabular}

The result confirmed findings from Quah [18] who highlighted the importance of a site survey in refurbishment projects. Site surveys are important since they determine the actual scope of work that had ambiguity in as-built design. They also confirm whether the existing building could be adapted for the proposed new uses.

The client's brief ranked second in the analysis; thus, it could be considered important as a method of obtaining information during the design process. Refurbishment projects dealing with the existing building require much information from the client who is more knowledgeable about their building than most other people. Thus, poor briefing by the client needs to be avoided since to it is a major factor interfering in the production of complete design and information for refurbishment projects.

The contractor's input scored moderately low and ranked second last among the method of obtaining design information. This reflects a lack of integration of the site team's personnel with the design team in the refurbishment projects. The contractor's input was considered important as a source of information for the refurbishment projects, particularly in some aspects of design such as the constructability of the existing building, as mentioned by Mitropoulos and Howell [16]. The involvement of the contractor enabled early identification of potential conflicts and could prevent major changes to the scope of works.

On the other hand, destructive and non-destructive tests were found to be the least important mean of information gathering during the design process of refurbishment projects. This result contradicted a study from Quah [18] who argued that the uncertain nature of refurbishment project required the use of nondestructive diagnosis techniques that were capable of increasing the accuracy of the survey results. The contradictory result indicates that refurbishment projects 
in this country are less uncertain, in the sense that most of the decisions could be made and confirmed through site observation only. Another possible explanation is that no funds were allocated by the clients for the designers to carry out any testing as a means of obtaining accurate information. This is probably because the cost of conducting the test is expensive.

The survey result shows the architects obtained relatively a high portion of their design information from the archive documents. The semi-structured interviews revealed that the architects still had to refer to the archive documentation as guidance for their design work for a number of reasons. First, some of the clients did not provide any extra fees for the architects to produce new measured drawings and site surveys. Detail measured drawings are not easy to prepare. For a large building, experienced building surveyors working with some other specialists such as land surveyors, structural engineers and mechanical engineers are required. Due to that limitation, the architects would use the available as-built drawings, records or in the worst-case scenario, simple sketches of the building floor plan could be made during the site visits.

The result in Table 2 shows that the design team input ranked fourth for the method of obtaining design information. This result showed that most architects still preferred to refer to the other consultants' opinion in refurbishment projects. It likely that, due to accountability and risk in the refurbishment projects such as variation claims, it is wise to share responsibility among the consultant design team's members. Normally, the consultants would advise thoroughly in their area of expertise and are accountable for their advice. Thus, sharing expertise could reduce some potential risks in the design.

The next analysis would be associative test between the methods of obtaining information on design performance of refurbishment projects. Three variables have been identified under the category of design performance. They are time variance, cost variance and percentage of completeness of design before work started on site. Since the data used for the test is ordinal data, Spearman rank correlation coefficient was employed in the test with null hypothesis would be rejected at 5 percent significance level. Prior to this a reliability test was carried out to check whether the data collected is reliable for data transformation. The result for Cronbarch's Alpha coefficient showed a reading of 0.82 , which indicates that the scale and data obtained is reliable, since the reading is more than 0.70 (Nunnaly [17]).

The results in Table 3 shows that two variables, 'design team's input' and 'destructive \& non destructive test' have positively correlated with percentage of completeness of design before work started on site at 5 percent significance level. This explained that the higher design team's input and testing carried out to get design information the higher percentage of completeness of design before work started on site for refurbishment projects could be achieved.

However, there is no correlation detected for method of obtaining information with cost and time variances for refurbishment projects. This result contradicted with RII result above where site survey and client brief are the most important methods in obtaining design information. 
Table 3: The Correlation Matrix between methods of obtaining information performance of design.

\begin{tabular}{lccc}
\hline $\begin{array}{l}\text { Method Obtaining } \\
\text { Information }\end{array}$ & $\begin{array}{c}\text { Cost } \\
\text { variance }\end{array}$ & $\begin{array}{c}\text { Time } \\
\text { variance }\end{array}$ & $\begin{array}{c}\text { \% of design } \\
\text { completeness before } \\
\text { work started on site }\end{array}$ \\
\hline Archive Document & .101 & .019 & .105 \\
Site Inspection & -.038 & -.038 & .058 \\
Client's Brief & -.175 & -.175 & -.175 \\
Design Team's Input & -.247 & .435 & $.435^{*}$ \\
Contractor's Input & .270 & -.075 & .285 \\
Destructive \& & .070 & -.170 & $.339^{*}$ \\
Non Destructive Test & & & \\
* Correlation at 5 percent significance level. & & \\
\end{tabular}

\section{Conclusion}

It could be concluded that a high degree of uncertainty requires the architects to be more proactive and knowledgeable in the process of finding out accurate information for their design works. Literature review shows the importance of information in the design process of refurbishment projects. Nevertheless, it has been a hindrance by the limitation in availability of information due to uncertainty nature of refurbishment projects. Ranking analysis using relative importance index (RII) method revealed that site surveys and client's briefs are the most important methods used by the architects, whereas testing is the least important among the methods of obtaining design information in refurbishment projects. However, result of associative test shows that the design team's input and testing had significant correlations with percentage of completeness of design before work started on site.

\section{References}

[1] Aho, T., Laatio, P. \& Lamsa, J., Refurbishment investment appraisal, Proceeding of international symposium on management, maintenance and modernization of building facilities, 18-20 November Singapore, CIB pp. 237-242, 1998.

[2] Ali A.S., Integrative mechanisms in the design process of building refurbishment projects. Unpublished $\mathrm{PhD}$ thesis, UiTM Shah Alam, Selangor Malaysia, 2008.

[3] Ali, A.S., Rahmat, I. \& Hassan, H., Involvement of key design participants in refurbishment design process, Facilities, Vol. 26No. 9/10, pp. 389-400, 2008 . 
[4] Baldwin A.N., Austin, S.A., Hassan, T.M. \& Thorpe, Modelling information flow during the conceptual and schematic stages of building design, Journal of Construction Management and Economics, Vol. 17, pp. 155-167, 1999.

[5] Bibby, L., Bouchlaghem, D. \& Austin S., Design management in practice: testing a training initiative to deliver tools and learning. Construction Innovation, Vol. 3, pp. 217-229, 2003.

[6] Bordass, W. \& Leaman, A., Design for manageability: Unmanageable complexity is a major source of chronic problems in building performance. Building Research and Information, Vol. 25, No.3, pp. 148-157, 1997.

[7] Bucciarelli, L.L., An ethnographic perspective an engineering design. Design Studies, Vol. 9. No. 3, pp. 159-168, 1988.

[8] Chan D.W.M. \& Kumaraswamy, M.M., A comparative study of causes of time overruns in Hong Kong construction projects, International Journal of Project Management, Vol. 15, No. 1, pp. 55-63, 1997.

[9] Chua, D.K.H., Tyagi, A. Ling, S. \& Bok S. H., Process Parameter-Interface Model for Design Management. Journal of Construction Engineering and Management Vol. 129, No. 6, 653-663. 2003.

[10] Daoud, O.E.K., The Architect/Engineer's role in rehabilitation work, Journal of Construction Engineering and Management Vol. 123, No. 1, pp. 1- 5, 1997.

[11] Egbu, C.O., Management education and training for refurbishment work within the construction industry, Unpublished PhD thesis, Department of Civil Engineering, University of Salford, UK. 1994.

[12] Friedman, D. \& Oppenheimer, N., The design of renovations. W. W. Norton \& Company New York, London, 1998.

[13] Mackinder, M. \& Marvin, H., Design decision-making in architectural practice, Information paper IP 11/82. Building Research Establishment, Watford, UK, 1982.

[14] McGeorge, F., Design Productivity - A quality problem, Journal of Management in Engineering, Vol. 10, pp. 350-367, 1988.

[15] McKim, R. Tarek, H. \& Attalla, M., Project Performance Control in Reconstruction Project. Journal of Construction Engineering and Management, Vol. 126, No. 2, pp. 137-141, 2000.

[16] Mitropoulos \& Howell, Renovation projects: Design process problems and improvement mechanisms, Journal of Management in Engineering, Vol. 18, No. 4, pp. 179-185, 2002.

[17] Nunnaly, J.O., Psychometric theory. New York: McGraw Hill, 1978.

[18] Quah, L.K., An Evaluation of the risks in estimating and tendering for refurbishment work. Unpublished $\mathrm{PhD}$ thesis, Herriot Watt University, Edinburgh, UK, 1988.

[19] Rahmat, I., The Planning and Control Process of Refurbishment projects, Unpublished PhD thesis, University College London. UK, 1997.

[20] Sivado, V. \& Norton K., Integrated Design Process Model, Journal of Management in Engineering, Vol. 10, pp. 55-62, 1994. 
Structural Studies, Repairs and Maintenance of Heritage Architecture XI 415

[21] Stermen, J.D., Systems dynamics modelling for project management, working paper, System Dynamic Group. Sloan School of management, Massachusetts Institute of Technology, Cambridge, MA, 1992. 